Urška Turk

UDK $81 ' 25=133.1=163.6: 81 ' 373.2$

Študentka Oddelka za prevajalstvo

Filozofska fakulteta Univerze v Ljubljani

urskaturk94@gmail.com
DOI: $10.4312 /$ vestnik.8.113-129

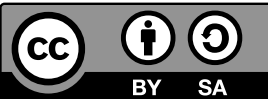

\title{
PREVAJANJE LASTNIH IMEN V PUBLICISTIČNIH BESEDILIH: PREVODI POIMENOVANJ FRANCOSKIH POLITIČNIH INSTITUCIJ V SLOVENŠČINO
}

UVOD

Namen članka je ugotoviti, kakšne so prevajalske strategije, ki se uporabljajo pri prevajanju lastnih imen iz francoščine v slovenščino na primeru francoskih političnih institucij v publicističnih besedilih. Naše ugotovitve se opirajo na analizo slovenskih prevodov francoskih časopisnih člankov s političnega področja, za primerjavo pa smo analizirali tudi poimenovanja francoskih političnih institucij v dveh osrednjih slovenskih časopisih.

Lastna imena so kulturnospecifična poimenovanja, kar pomeni, da so vezana na posamezno kulturo. To predstavlja težavo pri prevajanju, saj se mora prevajalec odločiti, ali bo kulturnospecifično lastno ime prevedel ali pustil v izvirnem jeziku. Ta odločitev je odvisna od konteksta in tudi od pričakovanega ciljnega občinstva. Publicistična poimenovanja političnih institucij so izrazito kulturnospecifična in novinarji jih uporabljajo predvsem zato, da se izognejo pretiranemu ponavljanju imen posamezne institucije in za ustvarjanje bolj razgibanega sloga. Pri njihovem prevajanju moramo presoditi, ali bodo bralci za razumevanje besedila potrebovali dodatno razlago. Z uporabo različnih prevajalskih postopkov besedilo približamo bralcem, ki niso seznanjeni z izhodiščno kulturo in tako besedilo naredimo bolj eksplicitno. Če pa presodimo, da ciljno občinstvo izhodiščno kulturo pozna dovolj dobro, lastno ime pustimo v izvirni obliki ali pa ga le prečrkujemo, da ustreza ciljnemu jeziku.

\section{LASTNA IMENA V SLOVENŠČINI IN FRANCOŠČINI}

V slovenščini so lastna imena del samostalniške besede (Toporišič 2004: 275), v francoščini pa so les noms propres del slovnične kategorije samostalnik (le nom) (Riegel et al. 1994: 320). Lastna imena poimenujejo bitja, predmete in kraje, vendar sama po sebi nimajo leksikalnega pomena, kar jih razlikuje od občnih imen, oziroma $\mathrm{v}$ francoščini les noms communs. Lastna imena imajo v obeh jezikih nekaj skupnih značilnosti; in sicer v 
obeh jezikih se zapisujejo z veliko začetnico, ne pojavljajo se kot slovarske iztočnice, se ne spreminjajo. Nimajo lastnega leksikalnega pomena in se nanašajo na edinstven nanosnik oziroma referent (Schlamberger Brezar in Perko 2011: 19-20). Kljub temu pa med slovenščino in francoščino obstaja nekaj pomembnih razlik, predvsem pri zapisu lastnih imen.

\subsection{Uporaba velike začetnice}

Publicistična poimenovanja političnih institucij spadajo v kategorijo stvarnih lastnih imen (SP 2001: 14-15). Ta se nadalje delijo na enobesedna in večbesedna stvarna lastna imena. V slovenščini enobesedna poimenovanja vedno zapisujemo $\mathrm{z}$ veliko začetnico (ibid.: 19), pri večbesednih poimenovanjih pa z veliko začetnico vedno zapišemo prvi del poimenovanja, drugi del pa le, če je ta sam lastno ime (ibid.). Tako v slovenščini zapišemo Elizej, Elizejska palača in Hotel Matignon.

V francoščini se pravilo za uporabo velike začetnice v splošnem ne razlikuje od slovenskega. Velika začetnica »se uporablja za ločevanje lastnih in občnih imen. Uporablja se za poimenovanja držav, ljudi, imen ulic, institucij ipd. » (Riegel et al. 1994: 171). Do razlike pa pride pri upoštevanju pravila, da se 'pomembne besede' zapisujejo z veliko začetnico. Odločitev, katere besede se obravnavajo kot pomembne, pa je subjektivna odločitev posameznega pisca (ibid.). V francoščini lahko ob upoštevanju tega pravila najdemo zapis Monsieur le Président de la République, kjer je z veliko začetnico zapisana tudi republika (la République). V slovenščino to poimenovanje prevedemo kot predsednik republike, kjer oba dela poimenovanja zapišemo z malo začetnico.

\subsection{Uporaba člena}

Slovenščina in francoščina se zelo razlikujeta pri uporabi člena. Slovenščina člena ne pozna, vendar je ta kljub temu pomembna kategorija pri prevajanju iz francoščine v slovenščino. V francoščini se lastna imena načeloma uporabljajo brez člena (Schlamberger Brezar in Perko 2011: 19-20), vendar obstajajo tudi lastna imena, pri katerih je uporaba določnega člena (l'article défini) obvezna. Ta je obvezen pri poimenovanju unikatnih referentov, kar so tudi poimenovanja političnih inštitucij. Tako je uporaba določnega člena pred poimenovanjem funkcije francoskega predsednika l'Élysée obvezna. Prevajalec se odloči, ali bo člen, ki je v francoščini obvezen, v slovenskem prevodu obdržal ali ne. To je pomembno vprašanje, če je kot prevajalska strategija uporabljena transferenca. V tem primeru se prevajalec odloči, ali člen ohrani tudi v slovenščini. 
Kot smo že omenili, jasnih pravil, kako prevajamo lastna imena, ni. Prevod je odvisen od ciljnega občinstva in tudi medija, kjer bo prevod objavljen. Publicistična poimenovanja se uporabljajo $\mathrm{v}$ publicističnih besedilih, ki so javna besedila in tako namenjena najširšemu občinstvu (Kalin Golob 2003: 40). To dejstvo moramo imeti pred očmi, ko se odločamo, katero prevajalsko strategijo bomo uporabili. Newmark (2000) predlaga nekaj prevajalskih strategij, ki so natančneje predstavljene v nadaljevanju.

Newmark (2000: 159-160) poda nekaj bolj splošnih smernic pri prevajanju kulturnospecifičnih poimenovanj, ki so povezana s političnimi institucijami. Če je naziv funkcije jasno razviden, kar pomeni, da je sestavljen iz zlahka prevedljivih ali mednarodno razumljivih delov, jih lahko prevedemo kar dobesedno in prevod je verodostojen (l'Assemblée nationale $\mathrm{v}$ narodno skupščino). Nekatere funkcije in politične institucije pa so poimenovane po zgradbah ali ulicah, v katerih imajo svoj sedež (na primer l'Élysée), zato ta poimenovanja neizobraženemu bralcu niso popolnoma poznana in lahko otežujejo razumevanje. Takšna poimenovanja lahko prenesemo, uporabimo uraden prevod ali pa razložimo.

Za prevajanje predvsem zemljepisnih lastnih imen Klinar (1994: 69) predlaga štiri strategije. Klinar sicer piše o prevajanju iz slovenščine $\mathrm{v}$ angleščino, vendar pa lahko njegove ugotovitve prenesemo tudi na prevajanje iz francoščine $\mathrm{v}$ slovenščino. Tuje poimenovanje lahko pustimo v izvirniku, ga v celoti prevedemo, prevedemo le občni del poimenovanja ali pa poimenovanje pustimo $\mathrm{v}$ izvirnem jeziku in prevodno ustreznico dodamo v oklepaju (ibid.: 70). V nadaljevanju kot primer navede prevod poimenovanja ljubljanske mestne hiše Magistrata v angleščino. Kot prevod predlaga the Magistrat (ibid.: 70); poimenovanje pusti v izvirnem jeziku in ga slovnično prilagodi angleščini z uporabo določnega člena. Sklepamo, da se ta strategija lahko prenese tudi na druge jezikovne pare in bi francosko poimenovanje l'Élysée prevedli kot Elizej. Tu pa se pojavi vprašanje, ali je ta prevodna strategija ustrezna za naše ciljno občinstvo (Reindl 2015: 216).

Prevodi publicističnih poimenovanj so, kot že omenjeno, namenjeni najširšemu možnemu občinstvu, zato mora biti prevajalec pozoren na to, da je prevod razumljiv vsem. $\mathrm{Z}$ drugimi besedami, svojega občinstva ne sme preceniti. Članke o francoski politiki, v katerih predvidevamo, da se pojavlja največ publicističnih poimenovanj političnih institucij, berejo tudi bralci, ki nimajo poglobljenega znanja o politiki, zato bi uporaba izvirnih poimenovanj lahko otežila njihovo razumevanje besedila.

\subsection{Prevajalske strategije}

Tu so predstavljene tiste strategije (Newmark 2000: 132-150), na katere se kasneje sklicujemo v analizi. Kombinacijo dveh prevajalskih postopkov Newmark imenuje dvojice (couplets). 


\subsubsection{Transferenca}

Prenos ali transferenca je prevajalski postopek, pri katerem kulturnospecifično poimenovanje iz izhodiščnega jezika le prenesemo v ciljni jezik. Ta postopek lahko vključuje še prečrkovanje. $Z$ uporabo transference dobimo najmanj komunikativen prevod in jo uporabimo le, ko smo prepričani, da ciljno občinstvo dobro pozna kulturo izhodiščnega jezika. Primer transference s prečrkovanjem je prevod l'Élysée v Elizej.

\subsubsection{Funkcijska ustreznica}

Funkcijska ustreznica je prevajalski postopek, pri katerem kulturnospecifični izraz izhodiščnega jezika prevedemo s kulturno nevtralnim izrazom ciljnega jezika. Primer funkcijske ustreznice je prevod francoskega izraza le Premier Ministre s slovensko ustreznico predsednik vlade. Ta postopek imenujemo kulturna komponentna analiza in je najbolj natančen način dekulturaliziranja kulturnega izraza. Zavzema osrednje področje med jezikom in kulturo izhodiščnega jezika ter jezikom in kulturo ciljnega jezika. Funkcijske kulturne ustreznice lahko uporabimo, če izraz v poljudnem članku ali poljubni literaturi ni ključna beseda in s tem pomagamo naslovniku, da se poistoveti z dogajanjem in si ga lažje predstavlja. So razmeroma redke, najdemo pa jih lahko tudi v dramskih besedilih.

\subsubsection{Kulturna ustreznica}

Kulturna ustreznica je prevajalski postopek, pri katerem kulturnospecifični izraz iz izhodiščnega jezika prevedemo s kulturnospecifičnim izrazom ciljnega jezika. To je le približni prevod, uporaba kulturnih ustreznic pa je omejena na splošna besedila, kjer natančnost prevoda ni tako pomembna. Lahko se uporabi tudi kot kratka razlaga za bralce, ki niso dobro seznanjeni s kulturo izhodiščnega jezika. Primer kulturne ustreznice je prevod sedeža francoskega predsednika vlade Hôtel Matignon v Matignonsko palačo.

\subsubsection{Direktni prevod}

Direktni prevod poznamo tudi kot kalkiranje in gre za postopek, pri katerem izraz prevedemo dobesedno. Takšni prevodi sicer niso preveč zaželeni, lahko pa zapolnijo vrzeli med dvema kulturama. Najbolj ustaljeni direktni prevodi so prevodi mednarodnih institucij, tako poimenovanje Communauté Économique Européenne v slovenščino prevedemo kot Evropska gospodarska skupnost.

\subsubsection{Opombe, dodatki, pojasnila}

Prevajalec mora včasih svojemu prevodu dodati še jezikovno ali kulturno informacijo, saj tako svojemu bralcu olajša razumevanje besedila. Dodajanje dodatnih pojasnil je odvisno od avtorjevih pričakovanj od svojega občinstva. Opombe, dodatke in pojasnila lahko v prevod dodamo na več načinov. Lahko se pojavijo v obliki pridevniškega stavka, 
samostalnika v pristavku ali pa med oklepaji. Primer opombe je slovenski prevod Matignon (sedež vlade).

\subsubsection{Opisna ustreznica}

Pri opisni ustreznici gre za prevajalski postopek, kjer je opis primerjan s funkcijo. Ta postopek imenujemo tudi opisni prevod. Tako je nož možen prevod mačete, saj je funkcija združena z opisom.

\section{$4 \quad$ PREVODI IZ ČASOPISA LE MONDE DIPLOMATIQUE}

V tem delu članka je predstavljena korpusna analiza publicističnega podkorpusa francosko-slovenskega korpusa FraSloK. Za analizo smo uporabili seznam publicističnih poimenovanj francoskih političnih institucij (Osrajnik 2014) in ga malo prilagodili. Poimenovanja smo preverili v slovenskih prevodih člankov iz francoskega časopisa Le Monde diplomatique, ki je edini francoski časopis, ki se vsaj deloma prevaja v slovenščino. Slovenski prevodi so dostopni kot vzporedni korpus na spletnem konkordančniku noSketch Engine. Ta podkorpus je le del prvega slovensko-francoskega korpusa FraSloK, ki je nastal v okviru doktorskega dela A. Mezeg (Mezeg 2013). Sestavljen je iz dveh podkorpusov, ki vsebujeta celotna besedila. Prvi je korpus publicističnih besedil, ki ga sestavljajo članki iz časopisa Le Monde diplomatique in njihovi slovenski prevodi, ki so bili objavljeni v časopisu Le Monde diplomatique v slovenščini med letoma 2005 in 2009 (ibid.). Drugi, literarni del korpusa pa sestavljajo sodobni francoski romani in njihovi prevodi v slovenščino. Prosto je dostopen le publicistični podkorpus, in sicer na spletnem konkordančniku noSketch Engine. Korpus je uravnotežen in del korpusa SPOOK, slovenskega prevodoslovnega korpusa (Vintar 2013).

\subsection{Rezultati}

Spodnja preglednica prikazuje rezultate analize publicističnega dela korpusa FraSloK. Številke v oklepajih označujejo število ponovitev posameznih pojavnic.

\begin{tabular}{|l|l|}
\hline Francosko poimenovanje & Slovenski prevod \\
\hline L'Élysée/Le Palais d'Élysée & Elizej (1) \\
\hline L'Hôtel Matignon/ Matignon & Matignonska palača (2), predsednik vlade (1) \\
\hline Le Palais Beauvau & Ni zadetka \\
\hline Bercy / Le Quai de Bercy & Ni zadetka \\
\hline
\end{tabular}




\begin{tabular}{|l|l|}
\hline Francosko poimenovanje & Slovenski prevod \\
\hline Le Quai d'Orsay & francosko Ministrstvo za zunanje zadeve (1) \\
\hline Le Palais Vendôme & Ni zadetka \\
\hline Le Palais Bourbon & Ni zadetka \\
\hline Le Palais du Luxembourg & Ni zadetka \\
\hline Le Président de la République & Predsednik Republike (5), predsednik republike (2) \\
\hline Le chef de l'État & $\begin{array}{l}\text { Predsednik države (4), voditelj države (5), šef } \\
\text { države (2), predsednik (2) }\end{array}$ \\
\hline Le Premier ministre & prvi minister (2), predsednik vlade (4), premier (4) \\
\hline Le Parlement & parlament (3), Parlament (1) \\
\hline Le Sénat & Francoski senat (1) \\
\hline L'Assemblée nationale & Francoska narodna skupščina (1) \\
\hline
\end{tabular}

Tabela 1: Podatki iz vzporednega korpusa

$\mathrm{V}$ prvem stolpcu so podana izvirna poimenovanja francoskih političnih institucij, $\mathrm{v}$ drugem stolpcu pa so pojavnice iz vzporednega korpusa FraSloK. Kot je razvidno iz preglednice, imajo nekatera poimenovanja več prevodov, kar pomeni, da je bilo pri prevajanju uporabljenih več različnih prevajalskih strategij. Pri analizi uporabljenih prevajalskih strategij smo dodali še primer iz korpusa.

\subsubsection{Prenos ali transferenca}

Prenos ali transferenca je uporabljen le pri enem poimenovanju, in sicer za prevod l'Élysée, ki je poimenovanje za urad francoskega predsednika. Poimenovanje je prevedeno kot Elizej, tu lahko opazimo tudi uporabo prečrkovanja, saj je prevajalec pisavo prilagodil slovenščini in slovenski izgovorjavi.

\section{Primer:}

Depuis son arrivée à l'Elysée, M. Nicolas Sarkozy n'a-t-il pas, à de nombreuses reprises, exprimé son intérêt pour ce pays et sa volonté de " donner une impulsion nouvelle au partenariat Europe-Ukraine », selon les termes du secrétaire d'Etat aux affaires européennes Jean-Pierre Jouyet?

Mar ni predsednik Nicolas Sarkozy od svojega prihoda v Elizej večkrat izrazil zanimanja za Ukrajino in pokazal svojo voljo, da bi »dal nov zagon partnerstvu med Evropo in Ukrajino", kot se je izrazil državni sekretar za evropske zadeve, Jean-Pierre Jouyet? 


\subsubsection{Prevod v slovenščino}

V slovenščino so z uporabo funkcijske ustreznice prevedena tri poimenovanja. Poimenovanje le chef de l'État je prevedeno s slovenskima ustreznicama predsednik države ali pa samo predsednik; drugo, uradno poimenovanje funkcije le Président de la République, je prav tako prevedeno s funkcijsko ustreznico kot Predsednik Republike in kot predsednik republike. Naslednja funkcijska ustreznica je prevod poimenovanja le Parlement, ki je preveden s slovensko ustreznico parlament. Tretja funkcijska ustreznica pa je prevod poimenovanja le Premier Ministre, ki je preveden s tremi prevodnimi rešitvami, in sicer kot Prvi minister, predsednik vlade in premier.

\section{Primer:}

Monsieur Nicolas Sarkozy ne parle quasiment plus d'écologie sans faire référence à l'" excellent livre de Jared Diamond, Effondrement ». A quatre reprises au moins, le président de la République a dit publiquement à quel point cet ouvrage l'avait impressionné.

GOSPOD Sarkozy skoraj ne govori več o ekologiji, ne da bi se pri tem skliceval na »odlično knjigo avtorja Jareda Diamonda z naslovom Effondrement (Propad civilizacij)《. Predsednik Republike je vsaj ob štirih priložnostih javno izrazil svoje navdušenje nad omenjeno knjigo.

Pri dveh prevodnih rešitvah lahko opazimo vpliv francoskega zapisa na uporabo velike začetnice v slovenščini. V prevodu Predsednik Republike sta oba dela poimenovanja zapisana $\mathrm{z}$ veliko začetnico, kar je sicer v skladu s francoskimi pravopisnimi pravili, vendar pa v nasprotju s slovenskim pravopisom. Gre za poimenovanje funkcije, kjer bi morala biti, glede na slovenska pravopisna pravila, pri obeh delih poimenovanja uporabljena mala začetnica. Tako pa je prevajalec pod vplivom francoščine pri obeh delih obdržal veliko začetnico. Drugi primer interference med francoščino in slovenščino je prevod Parlament. V francoskem izvirniku je uporabljena velika začetnica, kar je v skladu s francoskimi pravopisnimi pravili. V slovenščini pa se $\mathrm{v}$ tem primeru uporabi mala začetnica, torej je pravilnejši zapis prevoda parlament.

$\mathrm{S}$ funkcijsko ustreznico in kvalifikatorjem francoski sta v slovenščino prevedeni dve poimenovanji. To sta prevoda l'Assemblée nationale kot francoska narodna skupščina in le Sénat kot francoski senat. Poimenovanje s kvalifikatorjem francoski bralcem olajša razumevanje besedila, vendar je vse odvisno od konteksta. Če je iz sobesedila možno razbrati, da gre za Francijo in francoski politični sistem, je pretirana uporaba kvalifikatorja francoski lahko moteča. 


\section{Primer:}

“ Le maintien de Dagris dans la sphère de l'Etat [risquait] de l'exclure de certaines privatisations, les Etats africains s'opposant fréquemment à ce que des organismes majoritairement publics contrôlent les filières cotonnières privatisées ", précise un rapport du Sénat français, très favorable à sa dénationalisation, en mars 2005.

Poročilo v francoskem senatu marca 2005, ki je zelo naklonjeno denacionalizaciji družbe, zelo jasno navede: "Če Dagris ostane v državni sferi [tvegamo], da ga izločijo iz raznih privatizacij, ker afriške države pogosto ne dovoljujejo, da bi podjetja v pretežno javni lasti nadzirala uradno bombažno industrijo $v$ zasebnih rokah. «

V slovenščino je s kulturno ustreznico prevedeno poimenovanje l'Hôtel Matignon kot Matignonska palača. Prevajalec je francosko poimenovanje spremenil in namesto besede hôtel (hotel) v občnoimenskem delu uporabil poimenovanje palača. V francoščini ima beseda hôtel širše semantično polje kot hotel v slovenščini. Lahko označuje tudi pomembno zgradbo in se je v preteklosti uporabljala za označevanje prebivališča plemstva ali bogatih meščanov (Larousse). Z izbiro poimenovanja palača je prevajalec v slovenščino prenesel tudi ta drugi pomen besede hôtel. Poimenovanje palača je za slovenske bralce bližje funkciji uradnega prostora kot poimenovanje hotel. V francoščini obstaja tudi poimenovanje l'Hôtel de ville, kjer občnoimenski del prevajamo kot hiša, prevod v slovenščino je tako mestna hiša.

\section{Primer:}

C'est, par exemple, grâce aux largesses de grandes entreprises (Lafarge, Altadis, les AGF, EDF, Air France...), obtenues par l'entremise de M. Jean Peyrelevade, un ancien de Saint-Simon passé du cabinet de M. Pierre Mauroy à Matignon à la présidence du Crédit lyonnais, que "La république des idées » a pu voir le jour.

Tako gre na primer zahvala za to, da je Republika idej ugledala luč sveta, radodarnosti velikih podjetij (Lafarge, Altadis, AGF, EDF, Air France ...), pri katerih je posredoval Jean Peyrelevade, nekdanji "saint-simonovec «, ki ga je pot najprej privedla do kabineta Pierra Mauroya v Matignonski palači in nato v upravo banke Crédit lyonnais. 
V vzporednem korpusu je kot prevajalska strategija dvakrat uporabljen dobesedni prevod. Prevajalec se je zanj odločil pri prevodu poimenovanja funkcije predsednika države le chef de l'État. Dobesedna prevoda sta šef države in voditelj države. Poimenovanje le chef de l'État je zanimivo tudi z vidika konsistence. Je edino poimenovanje v vzporednem korpusu, ki je bilo v istem članku prevedeno na dva različna načina. Kot je razvidno iz spodnjega primera, prevajalec pri prevajanju ni bil konsistenten, saj je najprej uporabil funkcijsko ustreznico predsednik države, nato pa direkten prevod šef države.

\section{Primer:}

Car, loin d'être pour le peuple un "souverain captif”, le président bénéficie d'une concentration des pouvoirs et peut se passer de la légitimité du collectif: la responsabilité politique se dilue quand le chef de l'Etat se maintient malgré des échecs électoraux, législatifs ou référendaires).

Kajti predsednik za ljudstvo še zdaleč ni »suveren jetnik«, ampak ima v svojih rokah osredotočena pooblastila in se lahko požvižga na legitimnost kolektiva. Politična odgovornost oslabi, če se predsednik države navzlic volilnim, zakonodajnim ali referendumskim neuspehom obdrži na oblasti.

Comme l'avocat Roland Weyl, il propose notamment une réforme du statut du chef de l'Etat (p. 130) : immunité pénale, contrôle politique.

Prav kakor odvetnik Roland Weyl tudi on predlaga predvsem reformo položaja šefa države (str. 130): kazenska imuniteta, politični nadzor.

(Mercier, Jeremy, 2008 : La démocratie entre ruines et reconstruction)

Opisno sta v vzporednem korpusu prevedeni dve poimenovanji. Prvi je prevod poimenovanja L'Hôtel Matignon kot predsednik vlade. Tu je prevajalec presodil, da bralec nima zadostnega znanja o francoski politiki in mu je branje olajšal tako, da je publicistično poimenovanje opisno prevedel kot funkcijo. Drug primer opisnega prevoda je prevod le Quai d'Orsay kot francosko Ministrstvo za zunanje zadeve. Prevajalec je tu uporabil tudi kvalifikator francoski in tako prevod naredil še bolj razumljiv. Kot v prvem primeru je predvideval, da je samo publicistično poimenovanje bralcu slovenskega prevoda premalo znano. Pri uporabi opisnih prevodov moramo upoštevati ciljno občinstvo. Predvidevamo, da ta časopis berejo bralci, ki poznajo politično situacijo v Franciji in zato ne potrebujejo dodatne razlage $\mathrm{v}$ obliki opisnih prevodov in dodatnih kvalifikatorjev. 
Primer:

M. Bazire, auprès duquel les salariés de La Tribune sont venus plaider leur cause, le 11 juillet, a été directeur de cabinet à Matignon entre 1993 et 1995.

Bazire, na katerega so se zaposleni časnika La Tribune obrnili v svoji zadevi 11. julija letos, je bil vodja kabineta predsednika vlade v letih 1993-1995.

\subsubsection{Francoska poimenovanja brez zadetkov v korpusu}

$\mathrm{V}$ vzporednem korpusu ni bilo zadetkov za nekatera poimenovanja. To so le Palais Beauvau, Bercy/le Quai de Bercy, le Palais Vendôme, le Palais Bourbon, le Palais Luxembourg. Prevodov za ta poimenovanja ni zato, ker se v slovenščino prevajajo le članki, ki so pomembni za slovensko občinstvo. To pomeni, da se prevajajo le članki, ki omenjajo institucije, katerih odločitve lahko vplivajo tudi na slovensko politiko. S tem lahko pojasnimo zadetek le Quai d'Orsay (francosko zunanje ministrstvo) in neobstoječ zadetek za le Palais Beauvau (francosko notranje ministrstvo).

\section{$5 \quad$ PREVODI IZ ČASOPISOV DELO IN DNEVNIK}

Drugi del analize se osredotoča na poimenovanja, ki so uporabljena v izvirnih slovenskih besedilih, ki govorijo o francoski politiki. Tudi tu nas zanimajo prevajalske strategije, ki so jih uporabili slovenski novinarji. Večina člankov je povzeta po francoskih izvirnih člankih, zato predvidevamo, da je bilo tudi pri pisanju slovenskega članka potrebnega nekaj prevajanja, predvsem pri poimenovanjih institucij. V analizo so vključeni članki iz dveh osrednjih slovenskih časopisov Delo in Dnevnik, ki sta slovenski ustreznici francoskega časopisa Le Monde. Izraze v obeh časopisih smo iskali v osrednjem slovenskem referenčnem korpusu Gigafida. Vsako poimenovanje je preverjeno v obeh časopisih, pri pregledovanju pa smo opazovali način, kako je posamezno poimenovanje uporabljeno, oziroma, kako je prevedeno v slovenščino. Predvideli smo uporabo treh različnih strategij, in sicer opisni prevod v slovenščino, prenos poimenovanja v slovenščino brez dodatnega pojasnila in prevod poimenovanja v slovenščino skupaj s pojasnilom v kakršni koli obliki. Predpostavljali pa smo tudi, da obstajajo razlike pri poimenovanjih tudi med obema slovenskima časopisoma.

Podatki iz korpusa so razvrščeni glede na francoska poimenovanja, ki so bila uporabljena v prejšnjem delu analize. Podatki so predstavljeni v obliki preglednic, številke v oklepajih označujejo število posameznih pojavnic. 


\subsection{Le Palais d'Élysée}

\begin{tabular}{|l|c|c|}
\hline Izraz v korpusu & Delo & Dnevnik \\
\hline Elizej & 140 & 2 \\
\hline Elizejska palača & 189 & 176 \\
\hline V predsedniški palači v Elizeju & 1 & $/$ \\
\hline
\end{tabular}

Tabela 2: Le Palais d'Élysée

Poimenovanje Le Palais d'Élysée je publicistično poimenovanje za funkcijo francoskega predsednika države. V obeh slovenskih časopisih je največkrat uporabljena prevajalska strategija prenos ali transferenca. Razlika med Delom in Dnevnikom pa je uporaba enodelnega poimenovanja Elizej, kjer gre za transferenco poimenovanja l'Élysée. To poimenovanje ima v Delu le nekoliko manjšo pojavnost kot Elizejska palača, v Dnevniku pa se pojavi le dvakrat. Pojasnilo za to razliko je, da se poimenovanje l'Élysée uporablja manj pogosto kot polno poimenovanje, saj je manj transparentno. V Delu se pojavi tudi bolj razlagalni prevod $v$ predsedniški palači $v$ Elizeju.

\subsection{L'Hôtel Matignon/Matignon}

\begin{tabular}{|l|l|l|}
\hline Izraz v korpusu & \multicolumn{1}{|c|}{ Delo } & \multicolumn{1}{c|}{ Dnevnik } \\
\hline Matignon & \multicolumn{1}{|c|}{35} & $/$ \\
\hline & Matignon (sedež vlade) & palača Matignon \\
\hline & $\begin{array}{l}\text { Matignon, palača francoskih } \\
\text { premierov }\end{array}$ & $\begin{array}{l}\text { Matignon, sedež francoskega } \\
\text { predsednika vlade (2) }\end{array}$ \\
\hline & vladna palača Matignon (6) & $\begin{array}{l}\text { palača Matignon (rezidenca } \\
\text { francoskega premiera) }\end{array}$ \\
\hline & premierska palača Matignon & $\begin{array}{l}\text { pariški uradni sedež Hotel } \\
\text { Matignon }\end{array}$ \\
\hline & pariški hotel Matignon & vlada v palači Matignon \\
\hline
\end{tabular}

Tabela 3: L'Hôtel Matignon

Prenos ali transferenca je pri poimenovanju Matignon oziroma l'Hôtel Matignon je uporabljena le v Delu. V Dnevniku je uporabljena kulturna ustreznica palača Matignon. Vsa druga poimenovanja v obeh časopisih vsebujejo pojasnila in opombe. V Delu je uporabljena transferenca Matignon skupaj s pojasnilom v oklepaju. Uporabljana je tudi kombinacija kulturne ustreznice skupaj s pojasnjevanjem vladna palača Matignon, premierska palača Matignon in Matignon, palača francoskih premierov. Uporabljen pa je tudi direktni prevod skupaj s pojasnilom pariški (pariški hotel Matignon). V Dnevniku je uporabljena transferenca skupaj s pojasnjevalnim dostavkom (Matignon, sedež francoskega 
predsednika vlade), opisni prevod (pariški uradni sedež Hotel Matignon) in dvojica kulturne ustreznice in pojasnila (vlada v palači Matignon).

Tu lahko opazujemo različno uporabo velike začetnice pri zapisu besede hotel. V Delu je hotel zapisan z malo začetnico in je uporabljen kot občno ime, v Dnevniku pa so uporabili veliko začetnico in s tem nakazali, da gre za del lastnega imena. Razlika med časopisoma je vidna tudi pri uporabi transference (Matignon). To so uporabili le v Delu predvsem v Sobotni prilogi, medtem ko v Dnevniku izraz vedno pojasnijo in dodajo opombo.

\subsection{L'Assemblée nationale}

\begin{tabular}{|l|l|l|}
\hline Izraz v korpusu & \multicolumn{1}{|c|}{ Delo } & \multicolumn{1}{c|}{ Dnevnik } \\
\hline Assemblée nationale & $/$ & $/$ \\
\hline Narodna skupščina & 11 & 34 \\
\hline Francoska narodna skupščina & 3 & 23 \\
\hline
\end{tabular}

Tabela 4: L'Assemblée nationale

Za publicistično poimenovanje enega izmed domov francoskega parlamenta v nobenem od obeh časopisov ne uporabijo transference, torej ne uporabijo izvirnega izraza. To je razumljivo, saj l'Assemblée nationale ni zemljepisno ime kot prejšnji poimenovanji. Za to francosko poimenovanje je $\mathrm{v}$ slovenščini uporabljena funkcijska ustreznica narodna skupščina ali pa kombinacija funkcijske ustreznice in kvalifikatorja francoski (francoska narodna skupščina). V obeh časopisih je večkrat uporabljeno poimenovanje skupaj s kvalifikatorjem. V člankih, kjer ta ni uporabljen, je iz konteksta razvidno, da gre za francosko politično institucijo. Zanimiva razlika med časopisoma je poimenovanje l'Assemblée nationale v zgodovinskem kontekstu francoske revolucije. V Delu se pojavi le izraz narodna skupščina oziroma francoska narodna skupščina, iz česar lahko sklepamo, da so novinarji zgodovinsko poimenovanje prenesli na današnji l'Assemblée nationale in enačijo obe politični telesi. Novinarji Dnevnika pa za zgodovinsko poimenovanje glede na analizirana besedila dosledno uporabljajo poimenovanji francoska ljudska skupščina ali samo ljudska skupščina. Tako lahko opazimo, da ti poimenovanji v Dnevniku nista prekrivni in da novinarji med obema razlikujejo.

\subsection{Le Bercy/le Quai de Bercy}

\begin{tabular}{|l|c|l|}
\hline Izraz v korpusu & Delo & Dnevnik \\
\hline Bercy & 2 & $/$ \\
\hline & Gospodarsko ministrstvo v Bercyju & \\
\hline
\end{tabular}

Tabela 5: Le Bercy 
Le Quai de Bercy je publicistično poimenovanje za francosko ministrstvo z uradnim francoskim nazivom Le Ministère de l'Économie et des Finances (Osrajnik, 2014). Dobesedni prevod v slovenščino je Ministrstvo za gospodarstvo in finance, takšno ministrstvo pa v Sloveniji ne obstaja. V Delu se pojavita transferenca (Bercy) in kulturno funkcijska ustreznica (gospodarsko ministrstvo v Bercyju). Avtor članka je s tem besedilo približal bralcu in izpostavil tisti del ministrstva, ki se ujema s slovensko ustreznico. V Dnevniku zadetka za Bercy ni bilo, zato sklepamo, da se ta institucija v njihovih člankih pojavlja le $\mathrm{v}$ popolnoma opisnih prevodih.

\section{$5.5 \quad$ L'Orsay/Le Quai d'Orsay}

\begin{tabular}{|l|l|c|}
\hline Izraz v korpusu & \multicolumn{1}{|c|}{ Delo } & Dnevnik \\
\hline Quai d'Orsay & \multicolumn{1}{|c|}{14} & 3 \\
\hline & pariški Quai d'Orsay & \\
\hline & francoski Quai d'Orsay & \\
\hline
\end{tabular}

Tabela 6: L'Orsay

Le Quai d'Orsay je publicistično poimenovanje za francosko zunanje ministrstvo. Prenos ali transferenca se pojavi v obeh slovenskih časopisih, bistveno več jih je v Delu. Tako predvidevamo, da $\mathrm{v}$ tem časopisu od svojih bralcev pričakujejo dobro poznavanje francoske politike. V Delu se poimenovanje ponovi še s kvalifikatorjema pariški in francoski. Zadetek za Quai d'Orsay v Dnevniku lahko razložimo z domnevo, da je francosko zunanje ministrstvo za slovenske časopise pomembno, o njem dosti pišejo in zato predvidevajo, da so bralci z njim dobro seznanjeni.

\section{$5.6 \quad$ Le Sénat}

\begin{tabular}{|l|c|c|}
\hline Izraz v korpusu & Delo & Dnevnik \\
\hline francoski senat & 27 & 24 \\
\hline
\end{tabular}

Tabela 7: Le Sénat

Poimenovanje za drugi dom francoskega parlamenta se $\mathrm{v}$ dveh slovenskih časopisih pojavlja kot trasferenca s kvalifikatorjem francoski. Število pojavnic je v obeh časopisih skoraj enako. Kvalifikator francoski je poimenovanju senat najverjetneje dodan zato, da ne pride do zamenjave $\mathrm{z}$ drugimi političnimi telesi v Sloveniji in v tujini, ki imajo enako ime. Kot primer navedimo senat v Združenih državah Amerike in sodne senate v Sloveniji. Predpostavljamo pa, da je iz konteksta razvidno, o katerem senatu govoru članek, tako da je v večini primerov upravičeno zadosti le uporaba transference (senat), saj da kontekst bralcu dovolj informacij in tako izvirno poimenovanje ne vpliva na razumevanje besedila. 


\subsection{Poimenovanja brez zadetka v korpusu}

Tako kot v prejšnjem delu analize nekaterih poimenovanj v korpusu ni. Gre za poimenovanja le Palais Vendôme, le Palais Bourbon, le Palais Luxembourg in le Palais Beauvau. $\mathrm{V}$ primerjavi s prvo analizo, se v slovenskem korpusu Gigafida pojavi poimenovanje Bercy. Odsotnost ostalih poimenovanj pa razlagamo z domnevo, da te institucije niso tako pomembne za Slovenijo in slovensko politiko.

\section{$6 \quad$ ZAKLJUČEK}

Prevajanje lastnih imen je v veliki meri odvisno od konteksta in vrste besedila. Članek se osredotoča na prevajanje lastnih imen na primeru prevodov poimenovanj francoskih političnih institucij v slovenščino. Za njihovo prevajanje lahko uporabimo več različnih prevajalskih strategij. Rezultati korpusne analize so pokazali, da je pri člankih iz Le Monde diplomatique $v$ slovenščini, ki so bili v celoti prevedeni iz francoščine $\mathrm{v}$ slovenščino, največkrat uporabljena prevajalska strategija funkcijska ustreznica, in sicer pri treh poimenovanjih, dvakrat pa je uporabljena funkcijska ustreznica skupaj s kvalifikatorjem francoski. Transferenca se, presenetljivo, pojavi le enkrat. Pričakovali smo, da bo v prevedenih člankih večkrat uporabljena le transferenca, saj časopis berejo tisti, ki so seznanjeni s francosko politiko. Tu velja opozoriti tudi na dva primera interference med francoščino in slovenščino pri uporabi velike začetnice. Prevajalec v slovenščino je v dveh primerih ohranil veliko začetnico tam, kjer se glede na slovenski pravopis uporablja mala začetnica. Prav tako pa smo opazili, da pri časopisu Le Monde diplomatique v slovenščini pri prevajanju niso konsistentni oziroma nimajo urejene uredniške politike, saj sta $\mathrm{v}$ istem članku za prevod iste funkcije (le chef de l'État) uporabljena dva različna izraza oziroma dve različni prevodni rešitvi. Pri poimenovanjih v izvirno slovenskih besedilih pa med obema analiziranima časopisoma prihaja do razlik. V Delu večkrat uporabijo le transferenco, medtem ko v Dnevniku poimenovanje največkrat razložijo. Iz teh rezultatov izhaja tudi ugotovitev, da bi novinarji Dela od svojih bralcev lahko zahtevali zelo dobro poznavanje francoske politike in naj bi bilo občinstvo, kateremu so njihovi članki namenjeni, bolj izobraženo. Članki v Dnevniku so glede na rezultate analize namenjeni splošnemu občinstvu, saj je uporabljenih zelo malo transferenc, poimenovanja pa so pogosto razložena v oklepajih ali v pojasnjevalnih pristavkih. Iz tega lahko zaključimo, da sta pri prevajanju lastnih imen eden izmed najpomembnejših dejavnikov prav kontekst in ciljno občinstvo. Poleg tega pa predvsem v obeh slovenskih časopisih lahko opazimo težnjo po razlaganju poimenovanj, ki po mnenju prevajalcev bralcem niso poznana, ter po pogosti uporabi kvalifikatorja francoski, ki je na nekaterih mestih odveč, saj je iz konteksta razvidno, da članek govori o Franciji in francoski politiki. 


\section{LITERATURA}

KALIN GOLOB, Monika (2003) H koreninam slovenskega poročevalskega stila. Ljubljana: Jutro

KLINAR, Stanko (1994) Slovenska zemljepisna imena v angleških besedilih. Radovljica: Didakta.

MEZEG, Adriana (2013) Pridevniški polstavki v francoščini in prevedeni slovenščini. Vintar, Špela (ur.): Slovenski prevodi skozi korpusno prizmo. Ljubljana: Znanstvena založba Filozofske fakultete 94-118.

NEWMARK, Peter (2000) Učbenik prevajanja. Ljubljana: Krtina.

OSRAJNIK, Eneja (2014) Prevajanje imen francoskih političnih institucij v slovenščino. Diplomska seminarska naloga, Univerza v Ljubljani.

REINDL, Donald (2015) Contrastive Stylistics of toponymic representation in translation: Comments and Recommendations. Schlamberger Brezar, Mojca, Limon, David, Gruntar Jermol, Ada (ur.): Contrastive analysis in discourse studies and translation. Ljubljana: Znanstvena založba Filozofske fakultete 206-218.

RIEGEL, Martin/PELLAT, Jean-Christophe/RIOUL René (1994) Grammaire méthodique du français. Pariz: Presses Universitaires de France.

SCHLAMBERGER BREZAR, Mojca/PERKO, Gregor (2011) La morphosyntaxe non-verbale. Ljubljana: Znanstvena založba Filozofske fakultete.

Slovenski pravopis 2001. Ljubljana: Založba ZRC.

TOPORIŠIČ, Jože (2004) Slovenska slovnica (2. natis). Maribor: Obzorja.

VINTAR, Špela (2013) Uvodnik: O rojstvu korpusa SPOOK in njegovih prvih sadovih.

Vintar, Špela (ur.): Slovenski prevodi skozi korpusno prizmo. Ljubljana: Znanstvena založba Filozofske fakultete 6-9.

\section{Internetni viri}

Korpus FraSloK.

http://nl.ijs.si/noske/.

19. februar 2016.

Korpus Gigafida.

http://www.gigafida.net.

19. februar 2016.

Larousse.

http://www.larousse.fr/dictionnaires/francais/h\%C3\%B4tel/40476?q=hotel $\# 40386$. 10. november 2016. 


\section{Korpus FraSloK, kjer so posebej citirani naslednji članki}

ANCIBERRO, Jérôme (2008) Une communication habile au service d'un projet. Opus Dei, de la légende noire à la normalisation médiatique.

BENILDE, Marie (2007) Acheteur et marchand d'influence.

BENILDE, Marie (2008) Annonce de la suppression des recettes publicitaires. La télévision publique libérée de ses chaînes?

BONELLI, Laurent (2006) Quand Pierre Rosanvallon fustige un « déficit de compréhension $»$.

BOUCHER, Manuel/BOLZMAN, Claudio (2006) En Europe, à chacun son " modèle ». BOVET, Philippe, Sinaï, Agnès (2007) L'Atlas environnement.

CASTLETON, Edward (2009) L'infréquentable Pierre-Joseph Proudhon.

CHOLLET, Mona (2008) Show-business et politique en France. L'art de faire rêver les pauvres.

DE MONTLIBERT, Christian (2006) Universitaires à l'affût de parrains dans le privé. Et déjà une chaire L'Oréal au Collège de France!

GOANEC, Mathilde (2008) Après son échec au sommet de l'OTAN. L'Ukraine frappe à la porte de l'Europe.

JACQUIAU, Christian (2007) Max Havelaar ou les ambiguïtés du commerce équitable. JOURDE, Pierre (2008) Donner au public «ce qu'il demande ». La machine à abrutir.

LIAUZU, Claude (2007) Le ministère de l'hostilité.

MERCIER, Jeremy (2008) La démocratie entre ruines et reconstruction.

RAIMBEAU, Cécile (2007) Une autre Europe, celle des entreprises “ récupérées ”.

RAMONET, Ignacio (2006) Malade, la France?

REKACEWICZ, Philippe/VIDAL, Dominique (2007) Un tramway français nommé schizophrénie.

REMOND, Antoine (2006) Retour des vieux reves d'association entre le capital et le travail. L'épargne salariale ou comment flexibiliser les salaires.

RIMBERT, Pierre (2007) Sociétés de rédacteurs, un rêve de journaliste.

ROBERT, Anne-Cécile (2007) L'Afrique au kärcher.

ROUX, Mathias (2008) Mise en scène médiatique de l'opulence. Du pain, des jeux et des milliardaires.

TANURO, Daniel (2007) L’inquiétante pensée du mentor écologiste de M. Sarkozy.

TESTART, Jacques, APOTEKER, Arnaud (2006) De l'utopie scientifique au péril sanitaire.

VIDAL, Dominique (2006) Les raisons d'un vide.

WAHNICH, Sophie (2007) Extraditions : tolérance zéro ou clé. 


\section{POVZETEK}

Pričujoči članek se ukvarja s prevajanjem lastnih imen iz francoščine v slovenščino; natančneje, s prevodi publicističnih poimenovanj francoskih političnih institucij v slovenščino. Najprej predstavimo lastna imena $v$ slovenščini in francoščini ter relevantne razlike pri njihovem zapisovanju v obeh jezikih; nato pa omenimo še nekatere prevajalske strategije. Sledi korpusna analiza v dveh delih. Najprej smo analizirali publicistični podkorpus vzporednega korpusa FraSloK in nato še slovenski korpus Gigafida, kjer smo analizirali članke dveh slovenskih časopisov Delo in Dnevnik. Pri analizi smo se osredotočili na strategije, ki so jih pri prevajanju uporabili prevajalci. Poimenovanja v obeh slovenskih časopisih se med seboj razlikujejo in so odvisna od pričakovanega ciljnega občinstva. Pri poimenovanjih v prevedenih člankih smo pričakovali pogosto uporabo transference, vendar so ta pogosto prevedena $\mathrm{v}$ slovenščino ali pa opremljena $\mathrm{z}$ razlago, ki je $\mathrm{v}$ pomoč bralcem. Rezultati analize potrjujejo, da prav ciljno občinstvo in kontekst odločata o izbiri prevajalske strategije ter kažejo na prevajalčevo težnjo po dodatni razlagi pojmov.

Ključne besede: francoske politične institucije, prevajanje v slovenščino, lastna imena, publicistična besedila, prevajalske strategije

\section{ABSTRACT}

\section{Translation of the proper names in the journalistic texts: the translations of the names of} French political institutions to Slovene

This article focuses on the translation of proper names from French to Slovene; more specifically, on the Slovene translations of the names of French political institutions in journalistic texts. At the beginning, the proper names in Slovene and in French are presented together with the relevant differences between both languages and certain translation strategies. In the analysis, which consists of two parts, we first analyse the journalistic subcorpus of the parallel corpus FraSloK and then also the Slovene corpus Gigafida. The proper names in the two Slovene newspapers are translated differently and it is clear that the choice of the translation strategy depends on the target reader. In the news articles translated from French to Slovene, the expected translation strategy was transference, but the results show that the names are frequently translated to Slovene or explained to help the reader. The results confirmed that the context and the reader have the most influence on the choice of the translation strategy and they also show the tendency to explain those names that are likely considered to be unknown to the reader.

Key words: French political institutions, translation into Slovene, proper names, journalistic texts, translation strategies 